\title{
Trust in online advice
}

\section{Pamela Briggs $^{1}$ and Bryan Burford ${ }^{1}$}

Antonella De Angeli ${ }^{2}$, Paula Lynch $^{3}$ and Alexandra Trabak ${ }^{2}$

\author{
${ }^{1}$ University of Northumbria \\ Newcastle upon Tyne
}

NE1 8ST

+442274648

p.briggs@unn.ac.uk

\author{
${ }^{2}$ NCR Self-Service, AT\&R \\ Kingsway West, Dundee - UK \\ DD2 3XX, \\ +441382598325 \\ a.de_angeli@ncr.com
}

${ }^{3}$ PDD Ltd,

85-87 Richford Street,

London.

W6 7HJ

+44(0)2087351111 


\section{paulalynch@ppd.co.uk}

\section{ABSTRACT}

Many people are now influenced by the information and advice they find on the Internet, much of it of dubious quality. This paper describes two studies concerned with those factors capable of influencing people's response to online advice. The first study is a qualitative account of a group of house-hunters attempting to find worthwhile information online. The second study describes a survey of over two and a half thousand people who had actively sought advice over the Internet. A framework for understanding trust in online advice is proposed in which first impressions are distinguished from more detailed evaluations. Good web design can influence the first process, but three key factors - source credibility, personalisation and predictability - are shown to predict whether or not people actually follow the advice given.

\section{Keywords}

Trust, persuasion, advice, Internet, e-commerce. 


\section{INTRODUCTION}

In a world fraught with decisions, huge numbers of people are turning to the Internet for advice and guidance, with the result that online information is now exerting strong societal and personal influences.

In recent surveys in the USA, for example, nearly one person in eight said that online electoral information had affected their voting decisions [1]. While in the medical field, some 21 million people said that they had been influenced by the medical information they read on the Internet [2]. These numbers are staggering when one considers that people typically access health information via a general search engine, a process which cannot guarantee access to reliable sites.

The quality of information and advice available online can vary enormously. It has been estimated, for example, that less than half of the health and medical information available online has been reviewed by doctors [2]. So how do people decide whether or not to trust the advice they're given? Researchers have started to explore this question, with published studies available in the areas of online trust [3-11], and of Web credibility [Fogg $12-14]^{1}$.

These new studies are predominantly concerned with cataloguing those factors which enhance and those factors which diminish perceptions of trust and credibility. So far they have resulted in a number of guidelines or heuristics, and these have been brought together for the first time below:

\footnotetext{
${ }^{1}$ Credibility can be defined as 'trust in information' [12], a construct combining trust and expertise. However some models of trust incorporate a dimension of expertis e [20]. Since this paper is explicitly concerned with the process of seeking and acting upon advice, trust seems the more salient construct, since it presupposes action with some associated risk, whereas credibility seems more passive.
} 
1. Include seals of approval such as TRUSTe $[3,13]$

2. Provide explanations, justifying the advice given [10].

3. Include independent peer evaluation such as references from past and current users and independent message boards $[8,10]$.

4. Include alternative views, including good links to independent sites within the same domain[8].

5. Include background information such as indicators of expertise and patterns of past performance. [13,5,10].

6. Ensure that communication remains open and responsive and offer alternative means of getting in touch [10].

7. Improve ease of use $[3,5,10,13]$.

8. Create a professional image - avoiding spelling mistakes and other simple errors [13, 10].

9. Convey a 'real world' look and feel, for example with the use of real addresses and high quality photographs of real places and people [13].

10. Provide clearly stated policies, concerning, inter alia, security and privacy statements, rights to compensation and return. $[3,8,10]$

11. Don't mix advertising and content - avoid sales pitches and banner adverts [13].

12. Offer a personalised service, which takes account of each client's needs and preferences. [10].

These heuristics provide useful information for designers, however relatively few of them have been empirically tested. In addition, they have almost all focussed on a model of trust or credibility in a business-to-consumer (B2C) e-commerce environment, which is by no means the sole environment for online advice. 
A great deal more needs to be done to establish a convincing framework within which to understand trust in any domain, but this is particularly true of trust in online advice, given the important social consequences of Internet persuasion. Thus the purpose of this paper is to build and test a theoretically sound model for the study of trust in online advice.

Trust is a difficult construct, because it is hard to define, presupposing as it does an element of unspecified risk [4]. Exploring trust in online behaviour complicates the issue still further, since it invites considerations of source, message and channel. Some models recognise this in an explicit awareness that online trust entails questions about the control processes one must rely upon, as well as the agents one is dealing with [10,11]. While other models see trust as a composite of other, more accessible constructs, including faith, dependibility, reputation, predictability, familiarity and outcome expectancy. [10, 15,16,17]. A model which combines both viewpoints is MoTEC (A MOdel of Trust for Electronic Commerce) [10]. Trust in this model is initially determined by three factors: (a) the users knowledge of the domain and reputation of the vendor, (b) the impression made by the interface, and (c) the quality of the informational content as assessed by the user - although a forth factor becomes influential over time, in the relationship that an organisation eventually builds up with its client.

MoTEC holds that trust comprises both an impressionistic judgment of the interface and a more analytical evaluation of information content. This view gains support elsewhere [us] and reflects long-standing work which proposes two distinct cognitive processes underlying assessments of trust $[18,19]$. One process involves a heuristic or impressionistic judgement of the look and feel of the message or channel, while the other process involves a cognitively intensive and dynamic evaluation of the message content and source intention.

It seems likely that heuristic judgements of the look and feel of the interface will dominate initial judgements about the trustworthiness of advice sites on the Internet, but that more demanding analysis of content would 
come into play later. However most if not all of the studies available in the literature have been limited to first impressions. A typical paradigm, for example, is to give users a number of sites to visit and then ask for their views. Few, if any, studies have investigated real choices. In this paper, then, it is proposed that trust in online advice might be best investigated by looking firstly at those factors which influence first impressions of a website, and then at those factors which are more predictive of the uptake of advice. Two studies were conducted in order to provide information at both of these stages. The first study was a four-week field investigation of people's attitudes to online advice within a particular domain, while the second was a large-scale survey of trust in advice offered online.

\section{STUDY ONE: CONSUMERS’ TRUST IN ONLINE MORTGAGE ADVICE.}

\section{Method}

This section describes an in-depth qualitative study to explore consumers' attitudes to using the Internet as a source of advice for house-buying. Fifteen participants (eight female, seven male, aged between 27-35 years of age) were recruited. All participants were in their initial stages of house buying (e.g. they were all currently seeking advice on mortgage lenders, etc.) and used the Web at least once a week. The majority accessed the Internet at work and half had previously used newsgroups or message boards.

Each participant attended a total of four two-hour sessions held in an Internet café in London. In the first three sessions participants used the Internet to search for advice on house-buying related topics, followed by a group discussion with a facilitator. Participants were told to freely surf the Web during session one, and were directed to specific Websites during sessions two and three. During session four they took part in a group discussion and a group exercise. They were asked to record their perception of each site visited on a note pad, and use 
this information during the discussion sessions. All discussion sessions were transcribed and subject to content analysis.

\section{Results}

Participants defined advice as:

- a way to determine a course of action through other people's experiences;

- information that helps people make a decision; and

- information based on personal or professional experience and knowledge.

Participants had previously sought mortgage advice from specialist magazines and newspapers, word of mouth experiences from friends and family and from financial service providers. Most individuals showed some distrust of the advice from mortgage lenders - either being wary of small-print, or showing concerns about whether the advice given by potential lenders was in the interest of the borrower or of the lender.

Of particular interest in this study were users' first impressions of the trustworthiness of a site. During the first two sessions, participants visited over thirty mortgage websites. Table 1 provides a summary of those led to a positive versus a negative first impression.

Insert Table 1 about here

The comments made by users and the factors which influenced their early preferences clearly tie-in to the heuristics reported in the literature. However it is worth pointing out that in this study, there was no real support 
for heuristics 9 and 10 (real world 'look and feel' and clearly stated policies). Indeed, at least in terms of initial impressions, an overly corporate 'look and feel' was seen as disadvantageous, reducing as it did, a sense of independence and impartiality. Participants also showed some skepticism as to the value of branding in the advice domain, since the best advice was assumed to come from a truly independent source (although this may be a specific issue for financial advice):

"a brand makes it somewhat less trustworthy because all they are doing is looking for opportunities to sell their products, and they are not interested in finding the best mortgage deal for you" (male, 27 years old).

That is not to say that the 'look and feel' of the site was not important. Indeed, design issues seemed to exert a disproportionate influence on people's first impressions of the trustworthiness of a site, a finding which matches other observations within the cyber-banking sector [9]. This ties into the two-process model of trust described earlier. The first, heuristic or impressionistic process may be heavily influenced by the interface design, whereas the second, analytical process may tie-in to more complex judgments of expertise and motivation. A second study investigated these issues further.

\section{STUDY TWO: AN INTERNET-BASED SURVEY}

This second investigation was focussed upon those individuals who had genuinely sought advice over the Internet. As stated earlier, published models of online trust and credibility have been based upon initial impressions of websites, rather than upon their actual use. The study was therefore designed to (i) determine the demographics of people who had previously sought advice, (ii) determine the domains of advice sought, (iii) 
assess the relative importance of the various factors known to influence judgments of trust, and (iv) establish those factors most likely to lead to subsequent action.

\section{Method}

A web-based questionnaire, compatible with current versions of Netscape Navigator and Internet Explorer, was written in html, with data recorded by a cgi script written in Perl. On the first page participants were asked whether they had sought advice on-line, and those who clicked on 'yes' then completed 5 screens of questions. These requested: a) details of the site they had previously used (the subject and URL, if known, b) details of those subjects they had, would consider, and would not consider seeking advice for on-line, c) personal details for demographic comparisons, and d) questions about that site, derived from the trust literature and listed below:

1. The advice appeared to be prepared by an expert.

2. The advice came from a knowledgable source.

3. There were comments from other users on the site

4. The site was owned by well known brand and featured their name and logos.

5. I did not have to wait long for the advice.

6. Different options or alternative courses of action were suggested.

7. The site was easy to use.

8. I felt involved in the way the site tried to find appropriate advice.

9. The site was interactive.

10. The advice was tailored to me personally. 
11. The reasoning behind the advice was explained to me.

12. The site offered the opportunity to contact a person (by phone, email etc.).

13. The advice appeared to be impartial and independent.

14. I had used the site before.

15. The way the site went through the process of giving advice was predictable.

16. Using the site helped me make the right decision.

17. I trusted the advice.

18. I am knowledgeable about the subject area I was looking for advice about.

To express their opinion, participants had to click on a Likert-scale, ranging from 1 (disagree totally) to 7 (Agree totally). The questionnaire was promoted on thehungersite.com website, which at that time made a donation of 0.5 cents to the UN World Food programme for each impression an advertisement made on the hungersite page. Hungersite suggest that an average weekday will generate 300,000 impressions, and a clickthrough rate of $3 \%$. The URL for the questionnaire was also submitted to Yahoo and other search engines, and a press release was put out to print media.

\section{Results}

The section below refers only to participants who said that they had sought advice online. The data set was firstly cleaned-up by applying internal consistency checks to eliminate possible errors or fake answers (which can be a particular problem for research conducted online). Two hundred and sixty five respondents were found to be inconsistent in their replies, and they were discarded from the study, leaving a total of 2,893 respondents for the final analyses. 


\section{User Profile}

Fifty-eight per cent of the respondents were women. This reflects the current trend in Internet adoption - in the first quarter of 2000 the number of women online surpassed that of men for the first time ever in the US (Iconocast, 2000). However this may also reflect the fact that the survey was posted on the hungersite. The age distribution for men and women is illustrated in Figure 1.

\section{Insert Figure 1 about here}

Most of the respondents (32\%) looked for advice on medical issues or on education/career (26\%). The others were almost homogeneously spread between the legal/financial domain (10\%), computer (13\%), entertainment (10\%), and household (7\%). A very small minority was looking for personal advice (2\%). The distribution of domains as a function of the respondents' sex is illustrated in Figure 2.

\section{Insert Figure 2 about here}

\footnotetext{
A highly significant effect of sex emerged (Pearson $\chi^{2}=221.5, \mathrm{p}<.001$ ). Women were much more likely to seek advice on medical issues and family. Men, on the other hand, focused on computer and legal/financial issues. Nevertheless, some topics, such as household, education/career, and entertainment appeared to be gender neutral.
} 
The frequency distribution of the types of sites used for seeking advice is illustrated in Figure 3.

Insert Figure 3 about here

The majority of the sample sought on-line advice starting from portals. The vertical ones were the most commonly used (49\%), while the general ones were much less frequent $(10 \%)$. Almost $14 \%$ of the people sought advice on university or government sites. Corporate sites were seldomly used (9\%) and, as evinced by a crosstab analysis, they were mainly used for advice on computer. Eleven percent of the sample did not remember the name of the site used.

Responses to the 18 items of the trust-scale were subjected to a reliability analysis, to evaluate their consistency. The Cronbach value was satisfactory (standardised $\alpha=.81$ ). Nevertheless, four statements were only slightly correlated with the rest of the scale $(\mathrm{r}<.30)$. They were item 3 (There were comments from other user on the site), 4 (The site was owned by well-known brand and featured their name and logos), 12 (The site offered the opportunity to contact a person), and 18 (I am knowledgeable about the subject area I was looking for advice about). As regards the first three items, the problem can be attributed to a lack of a positive-negative direction of the statements. Comments from peer can be either positive or negative; a brand can be liked or disliked; a person can be expert or inexpert. Therefore, in a new version of the scale, these items should not be directly discarded, rather they should be reformulated. 
A global trust index was then computed, averaging scores to the 14 selected items. The variable was normally distributed and ranged from 1.2 to 7 . The mean reported trust value was 4.9 , significantly higher than 4 , the neutral scale midpoint $\left(\mathrm{t}_{(2664)}=50.89 ; \mathrm{p}<.001\right)$. To check the construct validity of the trust-scale, the index was analysed by a t-test with Action as the grouping variable. The rational behind the analysis is as follows: if the scale genuinely measures trust, it should differentiate people who took the advice on offer from people who did not. Results showed a highly significant effect of reported trust on action $\left(\mathrm{t}_{7777.71)}=21.51 ; \mathrm{p}<.001\right)$.

To further investigate the psychometric properties of the trust scale, a factor analysis was conducted. This technique is often used in data reduction to identify a small number of factors that explain most of the variance observed in a much larger number of manifest variables. The analysis was run applying the principaraxis factoring method with Varimax rotation. On the basis of a scree-plot analysis and of factor interpretability, three main factors were extracted. They accounted for $47 \%$ of the total variance and each had the eigenvalue index greater than 1.5. The interpretation of the factors was based on the semantic content of all the items presenting a saturation superior to .30 on just one factor. The rotated factor matrix is reported in Table 2.

Insert Table 2 about here

The first factor to emerge concerned source credibility. It concerned the extent to which the information and advice came from a knowledgeable source, was prepared by an expert, seemed impartial and was readily available. The trust item 'I trust the advice' also loaded on this scale. This factor was highly predictive of 
participants' decisions to follow the advice (see below) and it ties in very strongly to models of information credibility in the literature [Fogg et al, 2001].

The second factor concerned the extent to which the advice was personalised. Did the respondent feel involved in the process? Was the site interactive? Was the information tailored to the participant? Were different courses of action suggested, and was a peer commentary available?

Finally, the third factor was a measure of familiarity or predictability, and addressed the issue of whether or not the site met the user's expectations. Had the respondent used the site before and did they already know something about this domain? Did the site operate in a predictable way? Was it branded with a familiar name and/or logo?

\section{Taking advice}

A very high percentage of the respondents declared that they took the advice (78\%). This fits recent research on the influence of online information [1,2]. It is worth noticing that people trusted university, organisations, and government institutions more than any other type of sites. Those using university sites reported that they followed the advice given some $86 \%$ of the time. Naturally, the extent to which participants were prepared to take the advice offered was dependent upon perceived risk. A Mann-Witney U test showed that participants who took the advice felt they were risking less than participants who did not take it $(U=574297.0, p<.01)$.

What further factors predict the acceptance or rejection of the advice on offer? To ans wer this question a binary logistic regression was conducted. The analysis is similar to a linear regression but is suited to model 
where the dependent variable is dichotomous. Hence, it allows predicting whether an event will or will not occur, as well as identifying the variable useful in making the prediction. The estimated coefficients from the logistic regressions are reported in Figure 5.

The logistic regression demonstrated that all three of the trust factors previously identified - Source credibility, Personal tailoring and Predictability - significantly affected behaviour $(\mathrm{p}<0.001)$. Of the three, the role of source credibility is probably best-documented in the persuasion literature $[12,13]$ and this finding demonstrates that it is a crucial predictor of subsequent action. Here, too, is new evidence of the significant influence of personalisation and predictability on advice-taking. 


\section{SUMMARY AND DISCUSSION}

Two studies have been presented. In one, people actively seeking advice on buying a house were invited to visit a number of Internet sites. Their preferences reflected most of the design heuristics reported in the introductory section, although it was notable that the 'look and feel' of the interface exerted a very strong influence.

In the second study such design factors were less important. Demographic details were presented of over two and a half thousand people who had genuinely used the Internet to seek advice. The factors which they found influential in seeking online advice fell into three categories, each of which exerted a significant influence upon their decision to accept or reject the advice on offer: source credibility, personalisation and predictability. Of the three, source credibility was clearly the most influential.

The two studies combined do offer some support a two-process model of trust in online advice, in which both first impressions and subsequent analysis combine to create a sense the trustworthiness of a particular site. These processes have also been defined in terms of attraction and respect [21], terms which capture most of the design heuristics listed in the introductory section.

In terms of design recommendations, it is clear that the look and feel of a website is paramount in first attracting the attention of a user, and signaling the trustworthiness of the site. The site should be easy to navigate and free of errors and clutter - either from text or banner adverts. It should make allegiances clear, signal the services it offers, and should include obvious links to alternative views or products.

Other factors then take over. Users are likely to take the advice offered if the site is: 
(a) credible (demonstrates knowledge and expertise, appears impartial and ensures information is accessible),

(b) personalised (which means the site must be interactive, such that advice can be tailored to the individual, and users can make their own choices), and

(c) predictable (draws upon prior experience with this and other sites, reflects users' knowledge and understanding and contains the appropriate signs, statements or logos).

The importance of the first factor (source credibility) has been documented in the persuasion and online trust literature, but the significance of the other two factors is less widely accepted. The third factor (predictability) is particularly interesting when one considers that people searching for advice online typically arm themselves with information from several sites. Within the medical domain, for example, it is not unusual for people to visit three or more sites for advice before making any decision [2], and yet this comparative, self-educational process has not been properly acknowledged within the literature. It might be interesting to explore the ways in which people's expectations vary as a result of the sites they initially visit.

This study has documented some of the factors which can influence people's perception of the trustworthiness of online information, and which can directly influence behaviour. These are important issues. The Internet is already exerting a huge influence on society, and there are few regulatory bodies to monitor the accuracy of online content. There are also vital ethical issues to consider in this work. Researchers like ourselves are uncomfortably aware that in setting forth the design factors underpinning trust in online advice, we are not just coming to a better understanding of human behaviour online, but we are also demonstrating just how authors of untrustworthy sites can make them appear more trustworthy! Some researchers have started working towards an ethics of persuasive technology which attempts to clarify these rather cloudy issues of responsibility, having taken the assumption that 'in the near future, persuasive technologies will be commonplace [14], but there is a 
long way to go. For the moment it seems worthwhile to understand just how and why people are turning to certain sources of online advice rather than others.

\section{REFERENCES:}

[1] Pew research center (2000). Youth vote influenced by online information: Internet election news audience seeks convenience, familiar names. Available at: http://www.pewinternet.org

[2] Pew Research Center (2000). The online health care revolution: How the Web helps Americans take better care of themselves. Available at: http://www.pewinternet.org

[3] Cheskin Research (1999). eCommerce Trust Study. Available at: www.studioarchetype.com/cheskin/

[4] Friedman, Kahn, P.H. Jr. and Howe, D.C. (2000). Trust Online. Communications of the ACM43(12), $34-40$.

[5] Olson, J.S. and Olson, G.M. (2000). I2I trust in e-commerce. Communications of the ACM 43(12), 4144.

[6] Resnick, P. Zeckhauser, R., Friedman, E. and Kuwabara, K. (2000). Reputaion systems. Communications of the ACM 43(12), 45-48.

[7] Cassell, J. and Bickmore, T. (2000). External manifestations of trustworthiness in the interface. Communications of the ACM 43(12), 50-56.

[8] Schneiderman, B. (2000). Designing trust into online experiences. Communications of the ACM 43(12), 57-59. 
[9] Kim, J. and Moon, J.Y. (1998). Designing towards emotional usability in customer interfaces trustworthiness of cyber-banking system interfaces. Interacting with Computers, 10, 1-29.

[10] Egger, F.N. (2000). Trust me, I'm an online vendor: towards a model of trust for e-commerce system design. CHI 2000 Conference Proceedings. New York: ACM SIGGHI.

[11] Tan, Y.H. and Thoen, W. (2000). Towards a generic model of trust for electronic commerce. International Journal of Electronic Commerce, 5 (2), pp61.

[12] Fogg, B.J. and Tseng, H. (1999). The elements of computer credibility. CHI 99 Conference Proceedings. New York: ACM SIGGHI.

[13] Fogg, B.J., Marshall, J., Laraki, O, Osipovich, A, Varma, C, Fang, N, Paul, J, Rangnekar, A, Shon, J, Swani, P and Teinen, M. (2001). What makes web sites credible? A report on a large quantitative study. CHI 2001 Conference Proceedings. New York: ACM SIGGHI.

[14] Berdichevsky, D and Neuenschwander, E. (1999). Toward an ethics of persuasive technology. Communications of the ACM, 42 (5) 51-58.

[15] Briggs, P., Tahim, H. and Burford, B. (2000). Predicting trust in computer-based interactions. In $e$ futures: Proceedings of BIT 2000.

[16] Bluhm, LH (1987) Trust, terrorism, and technology Journal of Business Ethics 6;.333-341

[17] Rempel, J.K., Holmes, J.G. \& Zanna, M.P (1985) Trust in close relationships Journal of Personality And Social Psychology 49; 95-112

[18] Chaiken, S. (1980) Heuristic versus systematic information processing and the use of source versus message cues in persuasion. Journal of Personality And Social Psychology, 39, 752-766 
[19] Chenguan, W. \& Shaffer, D. (1987) Susceptibility to persuasive appeals as a function of source credibility and prior experience with the attitude object. Journal of personality and Social Psychology 52, 677-688.

[20] Barber, B. (1983). The Logic and Limits of Trust. New Brunswick: Rutgers University Press.

[21] Simons, H, W., Berkowitz, N, N and Moyer, R.J. (1970). Similarity, credibility and attitude change: A review and a theory. Psychological Bulletin, 73, 1-16. 
Table 1: Positive and negative comments to some of the websites visited during the first two sessions.

\begin{tabular}{|c|c|}
\hline A positive first impression was linked to: & A negative first impression was linked to: \\
\hline - Clear layout and display & - Boring web design \\
\hline - Fast response times & - Banner adverts and distracting graphics \\
\hline - Independent advice & - Time consuming registration \\
\hline - Informative content & - Slow response times \\
\hline - Additional facilities such as mortgage & - Too much text \\
\hline calculator or step-by-step guide & - Complex layout \\
\hline - Information from other lenders & - Confusing terminology \\
\hline - Opportunity for communication by & - Lack of rationale \\
\hline other means & - Corporate 'look and feel' \\
\hline - Jargon buster & - Sales pitch for own brand products \\
\hline
\end{tabular}




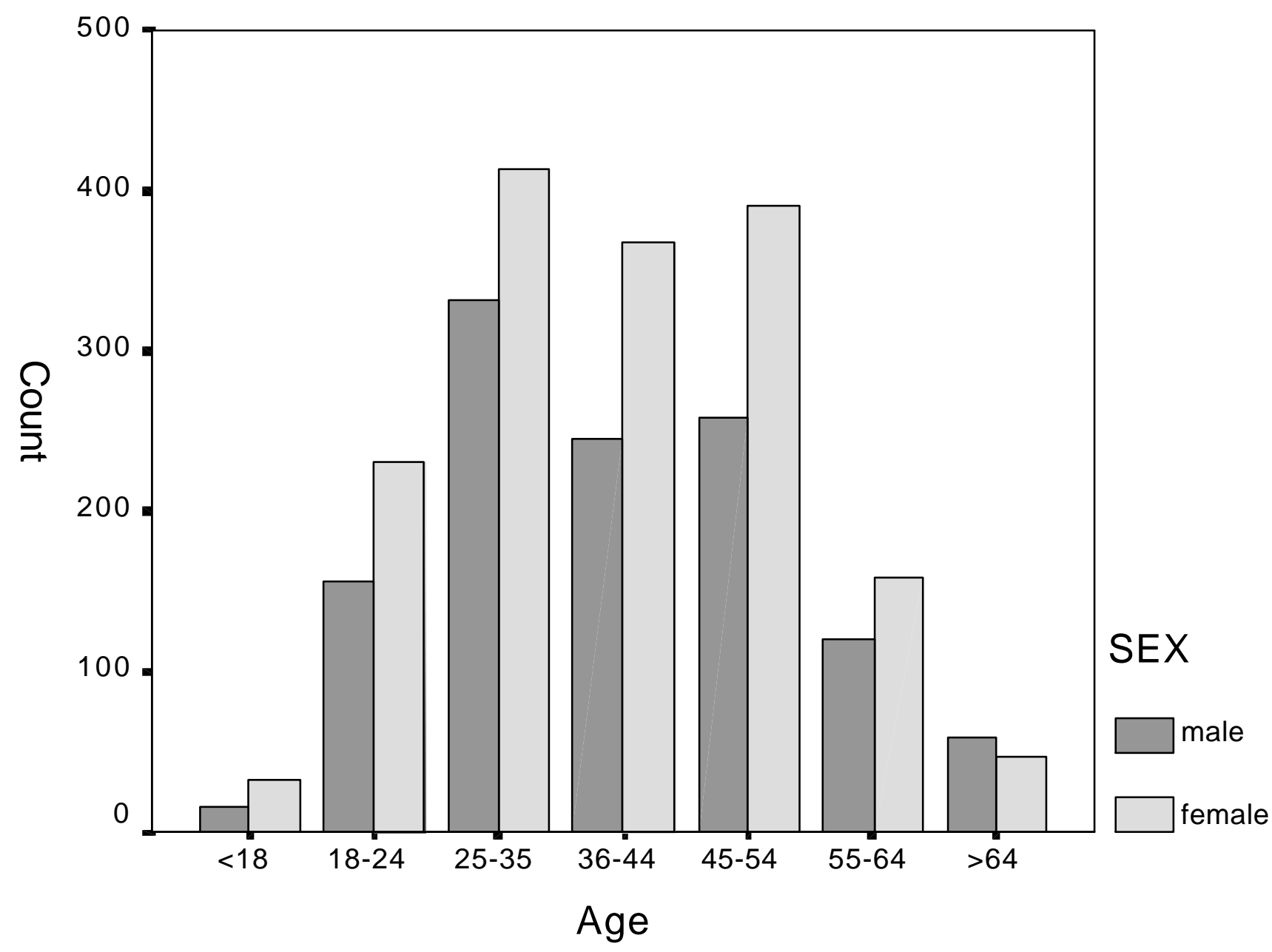

Figure 1: Distribution of participants by age and gender. 
Figure 2: Types of advice sought by gender

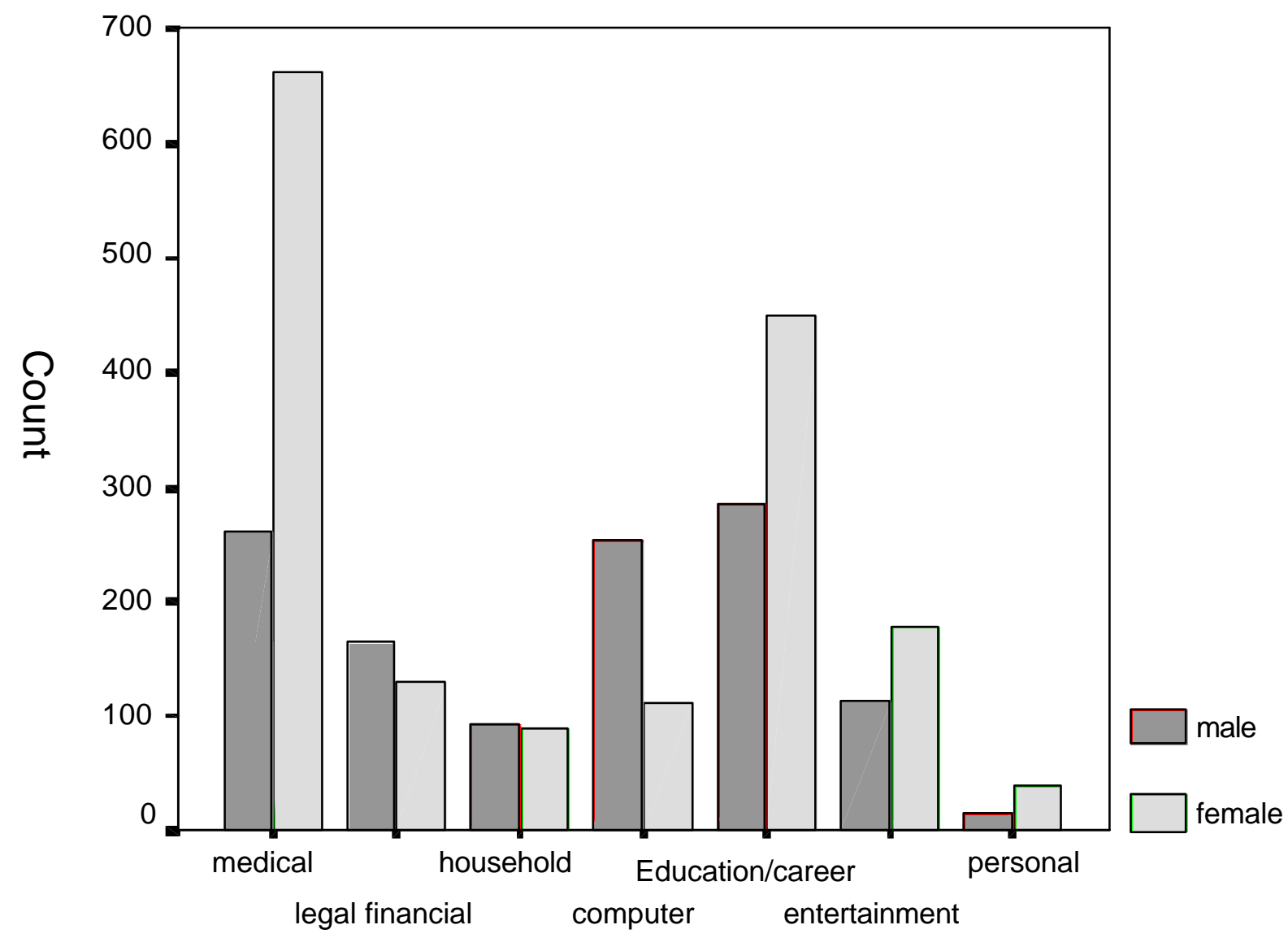

Advice domain 
Figure 3: Type of site visited.

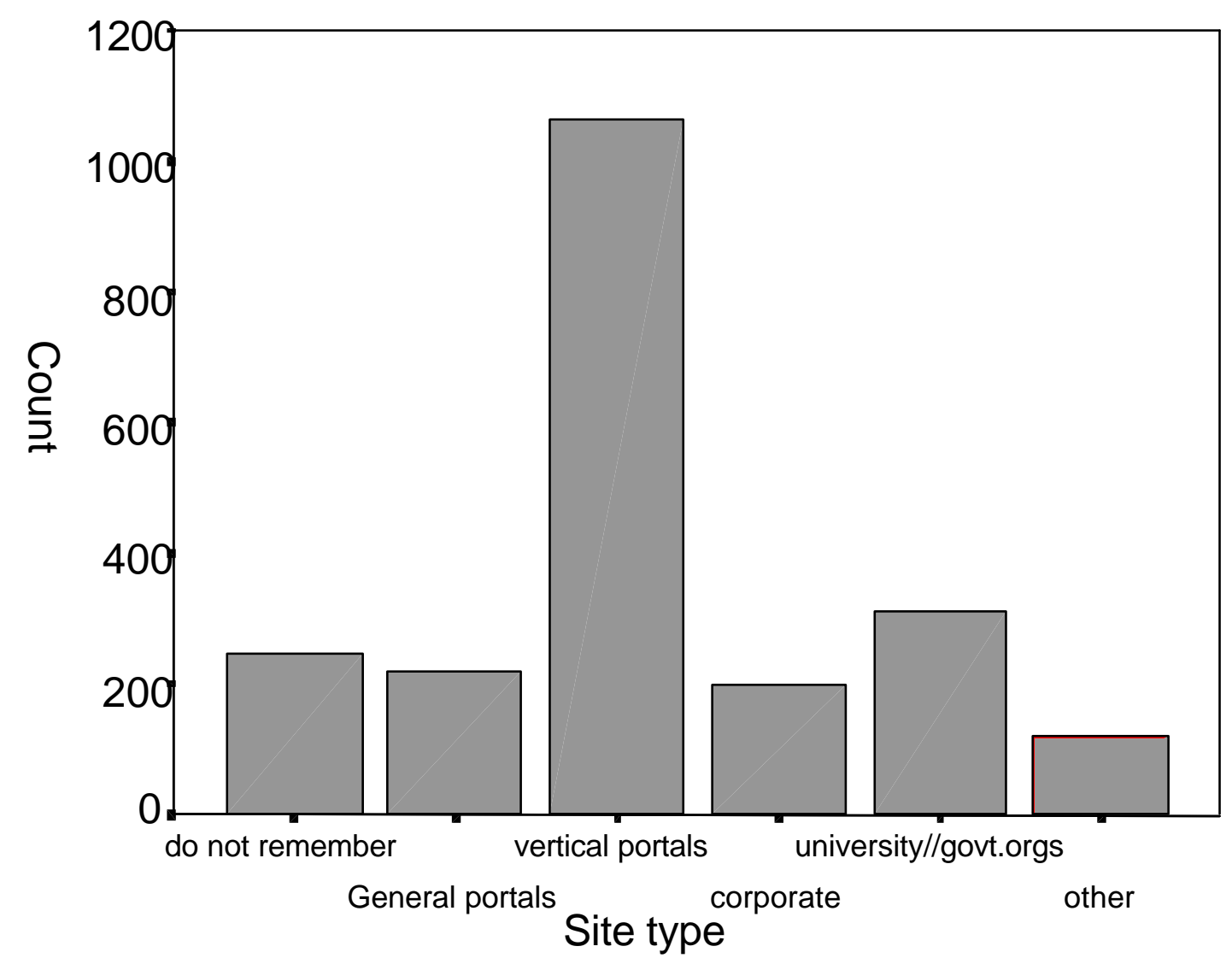


Figure 4: Relationship between self-reported trust and action.

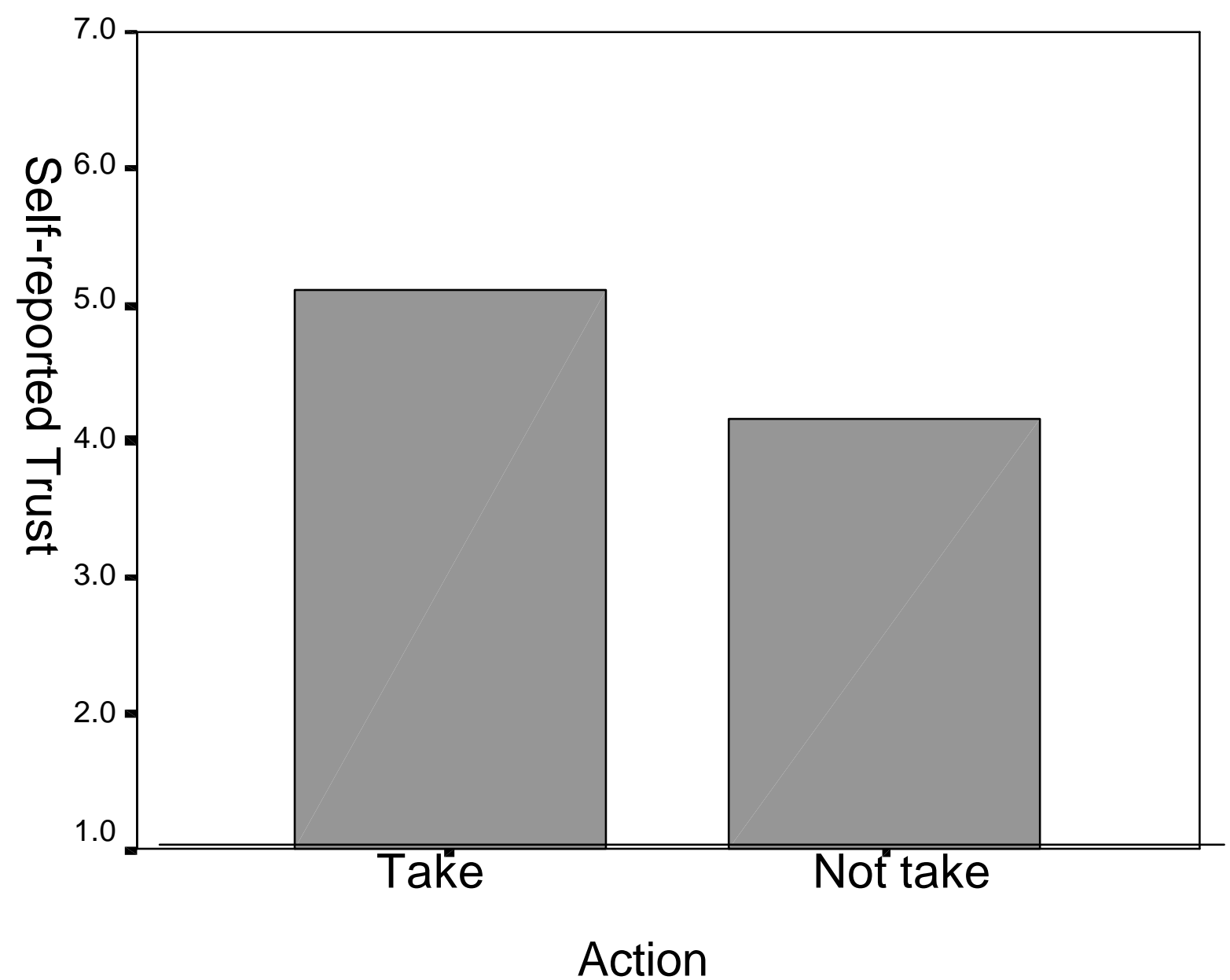


Table 2: Rotated factor Matrix (coefficients lower than .20 have been omitted).

\begin{tabular}{|c|c|c|c|}
\hline & Source credibility & Personalisation & Predictability \\
\hline 1 & .769 & & \\
\hline 2 & .807 & & \\
\hline 3 & & .416 & \\
\hline 4 & & & .363 \\
\hline 5 & .418 & .212 & .225 \\
\hline 6 & .249 & .442 & \\
\hline 7 & .375 & .397 & \\
\hline 8 & .253 & .666 & \\
\hline 9 & & .641 & .212 \\
\hline 10 & & .629 & \\
\hline 11 & .354 & .465 & \\
\hline 12 & & .244 & \\
\hline 13 & $.452^{*}$ & & \\
\hline 14 & & & $.722 *$ \\
\hline 15 & & & .532 \\
\hline 16 & $.566^{*}$ & .326 & .273 \\
\hline 17 & $.729^{*}$ & .209 & .202 \\
\hline 18 & & & $.355^{*}$ \\
\hline
\end{tabular}


Figure 5: Significant predictors of advice taking.

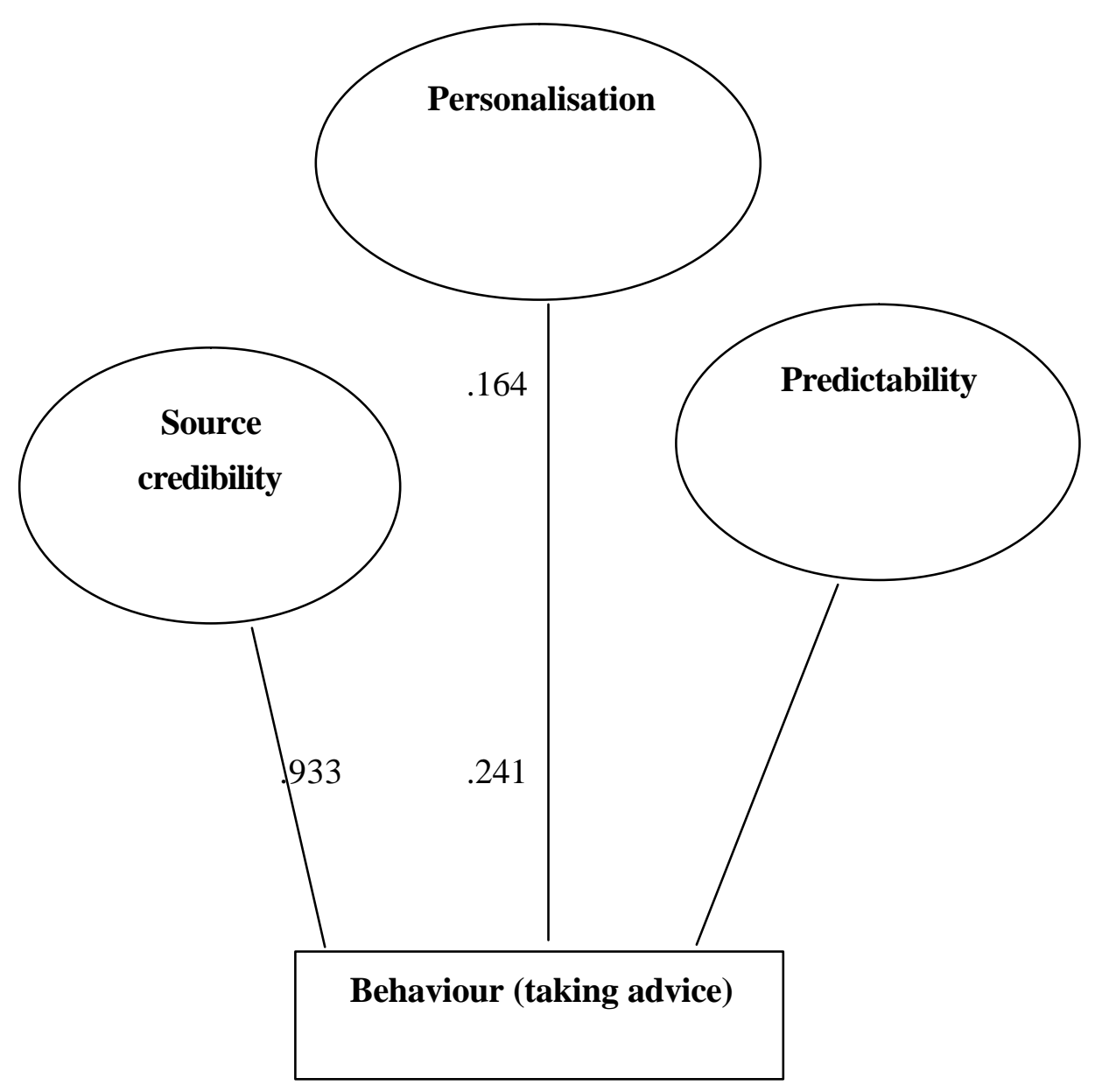

